\title{
(RE)-ORGANIZING THE EVOLVING HEALTHCARE MARKET: COLLABORATIVE GOVERNANCE IN BUREAUCRATIC CONTEXTS.
}

\author{
NICOLA MOUNTFORD \\ University College Dublin, \\ Belfield, Dublin 4, Ireland \\ SUSI GEIGER \\ University College Dublin, Ireland
}

\begin{abstract}
We explore the process through which 'strong' governments employ collaborative governance approaches as a response to evolutionary pressures in markets. We compare two such contexts, Ireland and New York, and find that pre-existing government roles in the market impact on the need to adopt a collaborative governance approach.
\end{abstract}

\section{INTRODUCTION}

Governance activities and processes are key to the organization of markets by specifying the parameters under which actors must operate, dictating the quality and quantity of the end product, and controlling the process and timing of its production (Bitzer, Francken, \& Glasbergen, 2008). When markets evolve, both their organization and their governance mechanisms are likely to change as well, but the literature on governance from within the organization science domain is largely silent on matters that transcend the corporate perspective (Tihanyi, Graffin, \& George, 2014). While researchers have extensively studied participatory and partnered governance approaches, they have largely done so in contexts of weak governance such as the developing world or international arenas where the public actor plays a limited role in the organization of the market. Research has also tended to center on markets that have historically been highly marketized but now require intervention in the name of the public good such as forestry or coffee. The markets that we seek to investigate are, however, characterized by 'strong' government in first world or industrialized nations. By strong, we refer to bureaucratic government that successfully legislates and regulates within its territory. These 'strong' governments are faced with modern challenges that are the reverse of those encountered in the developing world markets mentioned above and discussed in the collaborative governance literatures. Public goods such as energy, healthcare, communications and others are becoming increasingly marketized, where the methods and values of the market are now guiding policy creation and management (Eikenberry \& Kluver, 2004). Governments and other market actors seek to maintain societal considerations in the context of this re-organization.

Understanding the nature of market governance approaches, the conditions under which these transform, and the process by which new approaches emerge, is vital for organizations and their management seeking to understand the competitive underpinnings of such markets (Pettigrew \& Whipp, 1991). But in strong governance contexts, collaborative governance approaches go against the institutional grain, creating an interesting and important additional dimension in the organizational change of these markets (Battilana \& Casciaro, 2012). We combine our belief in market governance as a key element of market organization with Pettigrew's advice to consider change processes, social interaction, and context to offer a holistic 
and dynamic analysis of market evolution in markets characterized by traditionally strong public actor governance. We ask the following research question: How and why are markets (re)organized through the use of collaborative governance approaches in traditionally strong governance contexts? By addressing this question we contribute to literature on the organization of markets in two ways. First, we introduce governance concepts into market organization discussions, which have hitherto centered on more mainstream organization concepts such as collective identity (Liu, Gould, Rollins, \& Gao, 2014) or market categories (Pontikes \& Barnett, 2015). Secondly, we uncover the processes and activities of the public actor in the reorganization of public-good markets. We also add to the governance literature through a widening of the contexts in which collaborative governance approaches hold.

\section{LITERATURE REVIEW}

Governance constrains market actors and includes hard law, regulation, sanctions and moral rights (Midttun, 2008), market-based controls (Van Wijk, Stam, Elfring, Zietsma, \& Den Hond, 2013), self-regulation (Midttun, 2008; Midttun, Nikoloyuk, Burns, \& de Man, 2010), public policy (Lounsbury, Ventresca, \& Hirsch, 2003), and certification and standards (Burgess, 2014; Midttun, 2008; Van Wijk et al., 2013). Where government regulation is either absent or weakly controlled, partnership forms of governance may arise that are collaborative and cooperative rather than relying on sovereign powers of government (Cashore, Auld, \& Newsom, 2004; Nikoloyuk, Burns, \& de Man, 2010). These include policy, regulatory, and standardsetting processes that allow government to receive expressions of interests, exercises of rights and obligations, and collaborative activities to resolve differences, carry on activities and develop solutions and services (Waheduzzaman \& As-Saber, 2015). Such approaches emerged around the 1990s and have since been studied in environment-related sectors such as palm oil (Nikoloyuk et al., 2010), forestry (Cashore et al., 2004), water (Blackstock et al., 2015), coffee (Bitzer et al., 2008), and tourism (Van Wijk et al., 2013). Collaborative governance models enshrine joint definition of both ends and means, boasting "shared discretion" as a defining feature (Donahue \& Zeckhauser, 2011 p.45). Investigations of such collaborative governance approaches can be largely broken down into two key schools of thought: participatory governance and partnered governance. The participatory governance literature ${ }^{\mathrm{i}}$ generally deals with the involvement of individual publics in governance through "discrete, formal, governmentsponsored arrangements...that follow certain rules that have been set in advance... [having] a clearly defined beginning and end.” (Braun \& Schultz, 2010, p. 407). Partnered governance, on the other hand, has come to be associated with governance approaches instigated by "business players (enterprises) and other stakeholders in a sector", and more recently has moved towards the possible exclusion of the public actor (Nicoloyuk et al, 2010, p. 60).

It has been argued that the true seat of power in governance terms rests no longer with public actors but rather with commercial actors or the non-accountable global powers of fieldlevel institutions such as the world bank (Pestre, 2008). As market environments have become more complex and fast-changing, government's role in the regulation that might traditionally have reduced, penetrated or mediated this complexity has also changed (Child \& Rodrigues, 2011). Moreover exponential technological development and limited resources in the face of a rapid increase of 'big data' availability have often left government at a disadvantage vis-à-vis the industries they seek to control (den Hond, Rehbein, Bakker, \& Lankveld, 2014). We therefore contend that the contexts in which collaborative governance applies are extending from 'weak' 
into what would have been considered 'strong' governance contexts where government is weakened due to information asymmetries, dominant international governance structures, rapid technological development or other factors.

\section{METHODS}

In selecting a method with which to approach our research question we made three key decisions. Firstly, we selected a case study approach to allow us to address the 'how' and 'why' elements of our research question (Eisenhardt, 1989): how are collaborative governance processes used to re-organize markets that are facing evolutionary pressures, and why do traditionally strong and bureaucratic governments employ such collaborative approaches in particular market evolution contexts. Secondly, our longitudinal approach recognizes the embedded nature of market re-organization processes and the resulting need to "conceptualize and study the interactive field within which changes are emerging over time."(Pettigrew, Woodman, \& Cameron, 2001 p.688). Thirdly, we chose a comparative case study of two traditionally strong governance contexts in order to contextualize our findings (Eisenhardt \& Graebner, 2007; Seawright \& Gerring, 2008) and investigate and explain patterns - both similar and different - across the two (Ragin \& Amoroso, 2011).

\section{Research Setting and Case Selection}

The field of healthcare offers an ideal context within which to address questions that involve governance in evolving markets. It faces severe evolutionary pressures from technology (Caulfield \& Donnelly, 2013), institutional change (Reay \& Hinings, 2005), and sustainability concerns due to demographic change and resource limitations (Commission, 2014). We focus in particular on the increasing pervasiveness of technology in healthcare as an evolutionary force. The positions of existing actors and institutions change: patients become more informed, services shift to community rather than hospital based organizations, and data owners and analysts take on a new importance. Relationships between actors are disrupted - patients flow to community organizations rather than hospitals, information flows to patients and governments in different quantities and in different ways, patient and citizen influence increases with more information and access to direct media channels such as Facebook and Twitter. We focus on two markets facing such evolutionary change - The Republic of Ireland (ROI), and the State of New York (NY). We chose these two markets as the public actor in both markets has made its intention to re-organize the market clear in public statements and policy documents. At the same time, the two territories offer interesting divergences as to the role of the public actor in the organization of the healthcare market. In Ireland, the government plays a central role in the provision of healthcare services while in NY the state plays a minimal role in healthcare delivery.

\section{Data Sources}

Interviews: We conducted a total of 46 semi-structured interviews with 54 representative healthcare market actors (in the widest sense) affected by the technological evolution of the market including healthcare providers, government, pharmaceutical companies, technology firms, non-profit organizations, academia, field experts, and patients. The interviews were usually performed face-to-face with a small number taking place over skype and averaged between 30 minutes to 1 hour. Each interview was recorded and transcribed verbatim except 6 where permission to record was not granted and copious field notes were taken instead. 
Governance documents: We accessed other documentation produced in the name of governance of the use of technology within the healthcare market including legislation, policy documents, and government-issued invitations to tender. We also examined documents that offered interpretations of governance by market actors such as the American Medical Association, the Office of the National Co-ordinator for Health Technology and political commentators such as Politico. In total, our database of documents ran to 546 pages.

Observations: The first author spent one month in NY attending events, meeting market actors and observing the activities of market actors with time spent both pre-and post-visit observing virtual market activity through twitter, mailing lists and webinars. In ROI, she has been immersed in the connected health market as particiant observer for four years.

E-mails and websites: The first author joined the mailing lists of the ROI and NY connected health ecosystem and working group. She collected102 e-mails (NY) between $28^{\text {th }}$ September 2016 and $5^{\text {th }}$ December 2017 and 48 (ROI) from $1^{\text {st }}$ November 2013 to $5^{\text {th }}$ December 2017. Analysis was also made of the relevant sections of the Office of the National Co-ordinator for Health Technology website that deal with governance issues (www.healthit.gov: 1,060 out of a total 22,000 pages) in the USA and the eHealth Ireland website in ROI (www.ehealthireland.ie: 24 out of a total 949 pages).

\section{Data Analysis}

Data analysis involved three broad steps. Firstly we ordered the material around the various actors in each case and thus created narrative accounts of the roles played by market actors in each territory, creating a "detailed story from the raw data" (Langley, 1999 p.695). Our second step was to inductively analyze the data to investigate the processes of governance within each case. Over multiple coding revisits, we developed a smaller number of themes that centered on process within which these first order concepts could be nested: Participation, capacity building, framing, structuring, innovation and monitoring. Processes can be distinguished into field level processes that provide the structure for new governance models, and actor-level processes that detail governance mechanisms and actors involved. Our third and final step involved cross-case comparison to develop a conceptual model of the process of collaborative governance in evolving markets. In particular we contextualize these roles to understand the conditions under which public actors are likely to turn to collaborative governance approaches.

\section{FINDINGS}

\section{Invited participation is focused on defining means rather than ends; and involves organizations rather than individuals.}

Ends-defining participatory practices are few and far between in our cases and, where they exist, are confined largely to the organizational actors and field level processes embodied in lobbying. There is a gulf between the engagement of organizations and the engagement of patients. Patients are not currently engaging in the use of the technology, giving them little standing or perceived value in terms of governance participation. Participation, both in the technology and ultimately in its governance, may well come down to who is paying for their care.

2. Capacity building focuses on human and technology capacity at field level and on funding capacity at actor level 
Capacity building across the cases focuses on human, technical, and financial resources. From a human capital perspective, Ireland requires external expertise at field level. Technical infrastructure processes dominate the NY connected health field with far less discussion of the human capital and learning processes required. Technically, Irish vendors see the challenge as getting to a "tipping point" of technology adoption but tendering process requirements (that appear only in the Irish context) are a source of frustration on both the public purchaser, and the commercial vendor side. Field -level funding processes vary starkly across the two cases. In New York funding is highly ends-directed, in the form of the DSRIP program.

\section{At the field level, framing processes center around policy while at the actor level they revolve around the allocation of funding.}

Framing processes are largely funding-based and non-participatory in NY. There are limited, often lobbying, roles for non-government actors in the development of field-level policy, but when NY actors wish to influence problem definition, they do so predominantly by offering funding to those who will work on that problem. The Irish government, through its establishment of the eHealth Ireland committee and the eHealth Ireland ecosystem, has formally created multi-actor channels for framing and problem definition processes at actor level.

4. Attempts by new market entrants to re-structure the existing market take the form of lobbying while efforts to structure new entrants from within the market take the form of tendering processes.

While NY looks to legislation to structure and direct field activities, ROI uses tendering and its dual position as payer/provider. While non-profit organizations influence ROI's eHealth policy through early, participatory lobbying, insurers and the AMA influence US reimbursement policy in later, structural lobbying. Tendering is now being used to structure the management of an eHealth ecosystem, the design of a health innovation center, and the interactions of industry and academia in the area of connected health. In NY, meanwhile, formal restructuring, particularly as a consequence of the Patient Protection and Affordable Care Act (ACA) or "Obamacare", featured processes of consolidation at multiple levels. As adoption rates near $100 \%$ for EHRs, thanks to government incentive programs, and given the huge costs associated with ripping out or replacing an EHR system, many smaller technology providers are struggling.

\section{Innovation enabling processes circle back to capacity building processes.}

Legislation can underpin the innovation process when properly wielded. In contrast, the tendering process is stymying innovation in ROI. While some of the best ideas that the health service has seen came from small companies, these are the very organizations that cannot bankroll the long innovation process. Innovative health-tech start-ups face all of the problems of start-ups in any sector - real estate, hiring, fundraising, but the number one problem is market access. For many of the large hospital groups, such start-ups are an irritation rather than a source of innovation. To this end, Health Technology Pilots in NY are conducted in utilizing a commercialization award from NY Economic Development Corporation. Health Technology buyers and sellers are connected during a twice-yearly half-day matchmaking session.

\section{Monitoring and standards are seen as both critical to, and the death of, market re- organization.}


Innovation and measurement processes are repeatedly linked by informants in both jurisdictions to requirements for connectivity and an underlying requirement for standardization and the use of standards as a governance practice. Our interviews demonstrate a favoring of policy in the ROI, and legislation and regulation in NY, with standards featuring prominently in both. Many healthcare standards go back 30 or 40 years such that in some instances, working to meet them has eclipsed a view of what they were set up to achieve. There is a sense that standard proliferation is limiting innovation. Ultimately, however, without standards, the data sharing and exchange processes so necessary for the adoption of connected health will never be possible.

\section{DISCUSSION AND CONCLUSIONS}

Traditionally, partnered and participatory governance have been used in markets that are heavily marketized in order to retrospectively insert public good considerations. We compare a public good market that is becoming more and more marketized across two jurisdictions: healthcare. In ROI government has traditionally held two roles in relation to healthcare. As governor, it controls and directs ROI's healthcare system. As healthcare provider it is a key player in the delivery of healthcare within that system. These two roles contribute to the need for a collaborative governance approach. Almost daily media focus on waiting lists, an ER and inpatient capacity crisis, the nursing home fair deal scheme, potential industrial action and other HR issues, combined with sustained criticism by politicians and other stakeholders of government as healthcare provider, has limited the reach and legitimacy of a traditional legislative governance approach. In such instances self-regulation and market based incentives are more compelling and effective. The NY state government, on the other hand, remains firmly in the role of governor, not straying into the provision of healthcare. In this context legislation and regulation feature more heavily. Recent moves towards provision involvement, in particular with the passing of ACA in 2010, coincide with a move towards collaborative governance to offset risk exposure and reduce resource requirements. Although much of the literature carves out a collaborative role for monitoring (Donahue and Zeckhauser, 2011) and compliance (Dacin et al, 2002), we see little evidence of co-construction of the monitoring processes across the two cases. Innovation processes emerge through the cases as inextricably linked with both capacity building and structuring. Innovation depends on the funding, technical and human capacities of the organizational field and becomes an iterative process punctuated by restructuring processes to reflect and accommodate the field and actor level innovations involved.

This paper offers a new perspective on market governance and market organization. We develop a holistic and nuanced process map for partnered governance approaches that takes account of public actor roles in the organizing and re-organizing of such markets. We focus on one market, connected health, with particular professional and market institutions. Future research examining collaborative governance approaches in public good markets underpinned by alternative institutions but facing a similar technology-driven evolution, such as city planning, would be important to further refine the model.

\section{REFERENCES AVAILABLE FROM THE AUTHORS}

\footnotetext{
' also referred to in such terms as 'collaborative governance', 'co-management', 'network governance', 'new public management' and others (cf. Gray, B., \& Stites, J. P. 2013. Sustainability through partnerships. Capitalizing on collaboration. Network for business sustainability, case study.).
} 